\title{
Comparação entre técnicas para determinação de açúcares solúveis em alimentos utilizados na nutrição de ruminantes
}

\section{Comparison of techniques for determination of soluble sugars used in feed for ruminant nutrition}

\author{
Cândida Camila dos Reis ${ }^{1 *}$; Douglas Sampaio Henrique ${ }^{2}$; Edimara Schervinski³; \\ Juliano Zanela'; Leonel Vinicius Constantino ${ }^{5}$; Rafael Dallo ${ }^{6}$
}

\section{Resumo}

O objetivo do presente trabalho foi avaliar duas técnicas para determinação de açúcares solúveis (fração CA) em alimentos utilizados na nutrição de ruminantes. Os alimentos analisados foram: cana-de-açúcar, capim estrela, milho moído e farelo de soja. Foi determinado o conteúdo de matéria seca (MS), matéria mineral $(\mathrm{MM})$, extrato etéreo (EE) e proteína bruta $(\mathrm{PB})$, para calcular a concentração de carboidratos totais das amostras. O teor de carboidratos solúveis foi determinado em 15 repetições de cada amostra, utilizando-se duas técnicas analíticas distintas: uma que se baseia na extração dos carboidratos solúveis e na suaquantificação por espectrofotometria após a complexação do açúcar com a antrona; e outra que consiste na utilização do fenol como agente complexador. O delineamento utilizado foi inteiramente casualizado e os dados foram submetidos à análise de variância bifatorial $(\alpha=0,05)$, sendo os fatores, os diferentes alimentos e as duas técnicas. Não houve diferença significativa para o fator técnica, mas houve efeito do fator alimento e para a interação alimento $\mathrm{x}$ técnica. Por isso, foram realizadas novas análises de variância para testar se havia diferença entre as técnicas em cada um dos alimentos. Apenas o farelo de soja não apresentou diferença significativa quanto ao teor de açúcar solúvel determinado pelas duas técnicas.

Palavras-chave: Análises bromatológicas, fracionamento de carboidratos, sistemas de alimentação

\begin{abstract}
This study aims to evaluate different techniques for determination of soluble sugars (fraction CA) in foods used for ruminant nutrition. Feed analyzed were: sugar-cane, bermuda grass, corn meal and soybean meal. Dry matter (DM), ash, ether extract (EE) and crude protein (CP) were determined to make possible the calculation of total carbohydrates concentration in the samples. The soluble carbohydrate fraction were determined in 15 repetitions of each sample by two different analytical techniques. One technique based on soluble carbohydrates extraction and its quantification by spectrophotometry after chelation of the sugar with anthrone; and another one that uses phenol as the chelating agent. The experiment were conducted in a completely randomized design and the data submitted to the two-factor
\end{abstract}

\footnotetext{
${ }^{1}$ Discente do Curso de Mestrado do Programa de Pós Graduação em Zootecnia, Universidade Tecnológica Federal do Paraná, UTFPR, Dois Vizinhos, PR. Bolsista CAPES/DS. E-mail: candidareis@zootecnista.com.br

2 Prof., Programa de Pós Graduação em Zootecnia, UTFPR, Dois Vizinhos, PR. E-mail: douglas@utfpr.edu.br

${ }^{3}$ Zootecnista, UTFPR, Dois Vizinhos, PR. E-mail: edimaraschervinski@gmail.com

${ }^{4}$ Químico, Técnico de Laboratório, UTFPR, Dois Vizinhos, PR. E-mail: julianoz@utfpr.edu.br

${ }^{5}$ Discente do Curso de Doutorado, Dept ${ }^{\circ}$ de Química, Universidade Estadual de Londrina, UEL, Centro de Ciências Exatas, Londrina, PR. E-mail: nel_qui_uel@hotmail.com

${ }^{6}$ Médico Veterinário. UFPR, Palotina, PR. E-mail: rafaelmiola@hotmail.com

* Autor para correspondência
} 
factorial analysis of variance $(\alpha=0.05)$, with the different feeds and the two techniques as factors. There was no statistical difference between techniques, but the effect of the feed and the interaction feed $\mathrm{x}$ technique were significant. So, a new analysis of variance was conducted to test the difference between techniques in each feed separately. Only soybean meal did not show statistical difference between the water soluble sugars determined by the two techniques.

Key words: Chemical analysis, carbohydrate fractions, feeding systems

\section{Introdução}

A produção de bovinos no Brasil é basicamente realizada sob condições nas quais as pastagens constituem importante fonte de nutrientes. Nesse sistema de produção, podemos associar o baixo desempenho animal ao baixo valor nutritivo das forragens, principalmente quando se trata de animais com elevada demanda de nutrientes (VAN SOEST, 1994). Essa constatação evidencia a importância da busca de melhor entendimento dos mecanismos que governam a digestão ruminal para o adequado aproveitamento das pastagens pelos animais (VIEIRA et al., 2000).

Nas forrageiras, os carboidratos perfazem cerca de 60 a $80 \%$ da matéria seca, sendo a principal fonte de energia para os seres vivos compreendidos nos primeiros níveis tróficos (FERNANDES et al., 2003a). Nos ruminantes, a energia proveniente dos carboidratos se torna disponível indiretamente, na forma de ácidos graxos voláteis, gerados pela ação microbiana nos compartimentos fermentativos e, diretamente, pela absorção de seus monômeros constituintes, nos intestinos desses animais (VAN SOEST, 1994).

Os carboidratos são nutricionalmente classificados em fibrosos (CF) e não fibrosos (CNF). Os CF são representados pela celulose e hemicelulose e sua taxa de degradação ruminal é lenta e variável; por isso, ocupam espaço no trato gastrintestinal (TGI). Os CNF são representados pelos açúcares solúveis, amido e pectina, sendo a sua degradabilidade no rúmenalta e pouco variável entre os diferentes alimentos (VAN SOEST, 1967; MERTENS, 1996). De acordo com a taxa de degradação, os carboidratos podem ser divididos em fração CA, rapidamente degradável (açúcares) sendo os principais a glicose e a sacarose; fração CB1, degradação intermediária (amido); fração CB2, degradação lenta (parede celular disponível) e fração $\mathrm{CC}$, não degradável (parede celular indisponível) (SNIFFEN et al., 1992; FERNANDES et al., 2003b).

Essas quatro frações de carboidratos são utilizadas pelo sistema de avaliação de dietas, desenvolvido pela Universidade de Cornell: CNCPS (Cornell Net Carbohydrate and Protein System, 2008), para calcular a quantidade de energia disponível às bactérias que fermentam $\mathrm{CNF}$, que por sua vez utilizam $\mathrm{NH}_{3}$, aminoácidos e peptídeos como fonte de compostos nitrogenados $(\mathrm{N})$, assim como às bactérias que fermentam $\mathrm{CF}$, cujo requisito em $\mathrm{N}$ é atendido apenas pela $\mathrm{NH}_{3}$ (FERNANDES et al., 2003b). Geralmente, as frações nitrogenadas têm sido determinadas por meio de métodos de solubilização, e suas taxas de digestão obtidas por diferentes técnicas, resultando numa grande variação nos resultados observados (PEREIRA et al., 2000). Da mesma forma, as frações de carboidratos podem ser determinadas aplicando-se técnicas diversas, cada qual com seus benefícios e inconveniências.

O presente trabalho teve como objetivo avaliar se uma técnica de análises de carboidratos menos laboriosa proposta por Dubois et al. (1956), pode ser adaptada para a determinação dos açúcares solúveis em água. Neste sentido, essa técnica será comparada com atécnica padrão desenvolvida por Deriaz (1961). 


\section{Material e Métodos}

O projeto foi realizado nas instalações do Laboratório de Fitossanidade, do Curso de Zootecnia da Universidade Tecnológica Federal do Paraná-Campus Dois Vizinhos - PR, no período de março a maio de 2011.

Os alimentos utilizados na pesquisa foram os volumosos: cana-de-açúcar (Saccarum spp.) e capim estrela (Cynodon nlemfuensis) e os concentrados: milho moído e farelo de soja. As amostras de cana-de-açúcar (somente o colmo, sem as extremidades) e capim estrela foram coletadas no mês de fevereiro e pré-secas em estufa de ventilação forçada de ar a $55 \pm 5^{\circ} \mathrm{C}$ durante 72 horas, sendo que as amostras de cana-de-açúcar foram trituradas em triturador forrageiro antes da pré-secagem. Após a pré-secagem, o material foi triturado com peneira de malha $1 \mathrm{~mm}$, sendo que o milho moído e o farelo de soja foram peneirados (peneira de malha $1 \mathrm{~mm}$ ) para melhor homogeneização das amostras, e assim determinado o conteúdo de matéria seca (MS), matéria mineral (MM), extrato etéreo (EE) e proteína bruta (PB) de acordo com Silva e Queiroz (2004). O teor de carboidratos totais (CT) foi estimado utilizando a equação (1) proposta por Sniffen et al. (1992).

$$
C T(\% M S)=100-(\% P B-\% E E-\% M M)
$$

Para a extração dos carboidratos solúveis foram utilizadas 15 repetições de cada alimento. Destas repetições foram transferidos $200 \mathrm{mg}$ para um frasco erlenmeyer de $250 \mathrm{~mL}$ e adicionado $200 \mathrm{~mL}$ de água destilada; os frascos com as amostras em água foram colocados em incubadora com mesa de agitação orbital (200 rpm), à temperatura ambiente, durante uma hora para a solubilização dos açúcares.

A determinação dos açúcares solúveis foi feita por meio de duas técnicas distintas. A técnica descrita por Deriaz (1961) determina os carboidratos solúveis em água por meio da espectrofotometria, realizada após a formação de um complexo azulesverdeado, gerado pelo aquecimento desses compostos em solução de antrona fortemente ácida. A solução de antrona foi preparada adicionando-se, lentamente, $760 \mathrm{~mL}$ de ácido sulfúrico, para reação com antrona em $330 \mathrm{~mL}$ de água destilada. Em seguida se adicionou $1 \mathrm{~g}$ de tiuréia e $1 \mathrm{~g}$ de antrona, e feita agitação, até dissolução completa da amostra.

Após a solubilização dos açúcares em água, o conteúdo foi filtrado em papel-filtro quantitativo de filtragem rápida, retendo-se aproximadamente 50 $\mathrm{mL}$ do líquido filtrado. Uma alíquota de $2 \mathrm{~mL}$ do filtrado foi depositada em tubo de ensaio $(150 \mathrm{~mm}$ $\times 25 \mathrm{~mm}$ ) com tampa rosqueável, sendo este tubo mantido imerso em banho de água e gelo durante 10 minutos. Em seguida, adicionou-se $10 \mathrm{~mL}$ da solução de antrona, lentamente para que ela escorresse pela parede do tubo formando uma camada abaixo do líquido filtrado. O tubo era agitado dentro do banho de água e gelo, para homogeneização de seu conteúdo, e, posteriormente, levado, com a tampa levemente fechada (sem vedar) à fervura, durante 20 minutos, tendo o cuidado de manter a água fervendo durante todo o período. Ao término desta fase, o tubo foi transferido para o banho de água e gelo, para que este alcançasse a temperatura ambiente o mais rápido possível. A leitura era feita no menor tempo possível, em espectrofotômetro, no comprimento de onda de $620 \eta \mathrm{m}$.

A equação-padrão, relacionando a absorbância e a quantidade de carboidrato solúvel, foi obtida a partir da diluição de uma solução de $0,8 \mathrm{mg} \mathrm{mL}^{-1}$ de glicose, preparada para uso imediato, em soluções contendo $0 ; 0,04 ; 0,08 ; 0,12 ; 0,16$ e $0,20 \mathrm{mg} \mathrm{mL}^{-1}$ de glicose. Em seguida, foram tomados de cada solução, em duplicata, $2 \mathrm{~mL}$, para que se proceda à transferência para os tubos de ensaio e seguidos os mesmos passos para determinação dos carboidratos solúveis juntamente com as amostras.

Para determinação segundo o método de Dubois et al. (1956), seguiu-se o mesmo procedimento descrito anteriormente para secagem, preparação da amostra e extração dos açúcares em água. Posteriormente, foi colocada uma alíquota de 0,5 
$\mathrm{mL}$ da solução em tubo de ensaio mais $0,5 \mathrm{~mL}$ de fenol $5 \%$ e $2,5 \mathrm{ml}$ de ácido sulfúrico, sendo que as amostras de cana foram diluídas em água $(0,25$ $\mathrm{mL}$ da amostra para 0,25 $\mathrm{mL}$ de água) a fim de diminuir as concentrações de açúcares solúveis para evitar problemas na leitura. Após o resfriamento, foi feita leve agitação e em seguida a leitura em espectrofotômetro a 490 ๆm.

O delineamento utilizado foi inteiramente casualizado e os dados foram submetidos à análise de variância (ANOVA bifatoriala 5\%de significância $(\alpha=0,05)$.

As variáveis foram analisadas utilizando o seguinte modelo estatístico:

$$
Y_{i j k}=\mu+T_{i}+A_{j}+T A_{i j}+\varepsilon_{i j k}
$$

em que, $Y_{i j k}$ representa a k-ésima repetição do j-ésimo alimento analisado pela i-ésima técnica, $\mathrm{k}$ variando de 1 a $15 ; \mu$ é a média geral; $T_{i}$ se refere à técnica laboratorial, com $\mathrm{i}=1$ para a técnica da antrona e $\mathrm{i}=2$ para a técnica do fenol; $A_{j}$ corresponde aos alimentos analisados, em que $\mathrm{j}=1,2,3$ e 4 representa os alimentos: cana-deaçúcar, capim estrela, milho moído e farelo de soja, respectivamente; $T A_{i j}$ é o efeito da interação entre técnica e alimento e $\varepsilon_{i j k}$ indica o erro aleatório associado a cada observação, com distribuição supostamente normal e independente $\operatorname{NID}\left(0, \sigma^{2}{ }_{j}\right)$.

\section{Resultados e Discussão}

Os valores encontrados para a concentração de MS, MM, EE e PB dos alimentos testados (Tabela 1) foram próximos dos obtidos por outros autores (MALAFAIA et al., 1998; PEREIRA et al., 2000; HASHIMOTO et al., 2007; FAVORETO et al., 2008; DIAS et al., 2008).

Tabela 1. Composição bromatológica e concentração dos carboidratos solúveis da cana-de-açúcar, capim estrela, milho moído e farelo de soja.

\begin{tabular}{lcccc}
\hline Composição* & Cana-de-açúcar & Capim estrela & Milho moído & Farelo de soja \\
\hline MS & 913,2 & 905,2 & 877,0 & 908,3 \\
PB & 36,16 & 143,47 & 90,03 & 487,96 \\
EE & 15,5 & 11,6 & 45,6 & 18,5 \\
MM & 43,4 & 79,3 & 22,1 & 75,9 \\
CT & 904,9 & 770,8 & 842,3 & 417,6 \\
CHOs & 228,17 & 11,70 & 22,91 & 113,40 \\
CHOstrona) $_{\text {(fenol) }}$ & 216,52 & 19,38 & 27,35 & 116,80 \\
\hline
\end{tabular}

* Valores expressos em $\mathrm{g} \mathrm{kg}^{-1}$

MS Matéria Seca; PB Proteína Bruta; EE Extrato Etéreo; MM Matéria Mineral; CT Carboidratos Totais; CHOs ${ }_{(\text {antrona) }}$ Carboidratos Solúveis determinados pela técnica da antrona; $\mathrm{CHOs}_{(\text {fenol) }}$ Carboidratos Solúveis determinados pela técnica do fenol.

Fonte: Elaboração dos autores.

Ao analisar os carboidratos solúveis da cana foi observado que a concentração era tão alta que ultrapassava a capacidade do espectrofotômetro. Essa constatação baseou-se no valor de absorbância obtido quando se usou o volume padrão de amostra recomendada na técnica de Dubois et al. (1956), ou seja, 0,5 mL de amostra. Com esse volume de amostra os valores de absorbância ultrapassaram 1,5 e as medições do equipamento variavam muito sem que houvesse a estabilização da leitura. Segundo, Bracht, Kelmer-Brach e Amado (2003) concentrações muito altas da substância a ser determinada escapam da faixa de linearidade entre concentração e absorbância e geralmente 
a linearidade torna-se problemática a partir de absorbâncias entre 1,5 e 2,0. Portanto, avaliouse várias diluições da amostra a fim de diminuir a concentração de açúcares solúveis e reduzir os erros de leitura do espectrofotômetro. O critério de escolha foi a diluição mínima necessária para encontrar valores de absorbância menores que 1,5; sendo escolhida a diluição de $0,25 \mathrm{~mL}$ de amostra para $0,25 \mathrm{~mL}$ de água.

Houve considerável variação nas concentrações de açúcares solúveis entre os alimentos analisados, o que confere diferenças importantes entre esses alimentos. A escolha dos alimentos com diferentes concentrações de açucares solúveis possibilita melhor avaliação dos limites das técnicas testadas.

O capim estrela, quando comparado com os outros alimentos analisados, apresentou baixa concentração de carboidratos solúveis, pelo fato das gramíneas, de modo geral, apresentarem de 60 a $80 \%$ de seus carboidratos sendo componentes da parede celular vegetal (VAN SOEST, 1994). Favoreto et al. (2008) pesquisando a mesma gramínea também encontraram baixas concentrações de carboidratos solúveis $\left(13,24 \mathrm{~g} \mathrm{~kg}^{-1}\right)$, por meio de ensaios in vitro de degradação gravimétrica da fibra, combinada à produção cumulativa de gases e de ajustes de modelos matemáticos. A exceção dentre as gramíneas é a cana-de-açúcar que apresenta elevada concentração de carboidratos solúveis, principalmente sacarose. No presente trabalho encontraram-se valores de carboidratos solúveis para cana-de-açúcar mais de 10 vezes maior do que do capim estrela (tabela 1) evidenciando assim a importância da cana como fonte de carboidratos de altíssima taxa de degradação ruminal. Silva et al. (2008) encontraram teores maiores de carboidratos solúveis na canade-açúcar (411,4 $\left.\mathrm{gkg}^{-1}\right)$, analisando caule e folhas. Muitos são os fatores que podem contribuir para essas variações, tais como o estado fisiológico da planta no momento da colheita, o genótipo, as condições ambientais durante seu desenvolvimento e a parte da planta que foi colhida (por exemplo, a base do colmo possui maior concentração de açúcares do que o ápice).

As concentrações de carboidratos solúveis do milho foram aproximadamente dez vezes menores do que da cana, o dobro do capim estrela e cinco vezes menores que do farelo de soja (Tabela1). Os teores de açúcares solúveis do milho variam de acordo com a maturidade fisiológica do grão, sendo que até o $15^{\circ}$ dia após a polinização as concentrações de sacarose aumentam rapidamente, depois diminuem e ocorre significativo aumento dos polissacarídeos totais durante todo amadurecimento $(\mathrm{CREECH}$, 1968), quanto mais maduro o grão menor será sua concentração de açúcar solúvel. Além disso, alterações nas concentrações de açúcares solúveis no grão de milho podem ser decorrentes da variedade utilizada. Caniato et al. (2007) encontraram valores de açúcares solúveis variando de 43,8 a95,2 g kg ${ }^{-1}$ em diferentes cultivares de milho, esses valores são muito superiores aos encontrados no presente trabalho, talvez pelo fato do autor ter utilizado grão verde, que como discutido anteriormente possui maior teor de açúcar.

O farelo de soja apresentou valores consideráveis de carboidratos solúveis, ficando abaixo apenas da cana de açúcar (tabela1). Dentre os fatores que podem alterar a concentração de carboidratos solúveis na soja, podemos citar a forma de extração do óleo, o tipo de solvente utilizado, o tempo e a temperatura de secagem (VIANNA; PIRES; VIANA, 1999). Bertipaglia et al. (2008) encontraram variações nas concentrações de carboidratos solúveis da soja in natura e em diferentes graus de extrusão (549 até $715 \mathrm{~g} \mathrm{~kg}^{-1} \mathrm{em}$ relação ao CT), quanto maior a temperatura de extrusão da soja maior a concentração de carboidratos solúveis. Hashimoto et al. (2007) encontraram concentrações bastante altas de carboidratos solúveis no farelo de soja (283,01 $\left.\mathrm{g} \mathrm{kg}^{-1}\right)$ quando comparadas ao encontrado no presente trabalho. No entanto esses autores não determinaram os $\mathrm{CHO}$ solúveis diretamente, mas calcularam essa fração pela diferença entre os $\mathrm{CHO}$ 
totais e as outras frações de carboidratos, conforme sugerido por Sniffen et al. (1992). Desta forma, todos os erros das outras analises para determinar as frações de carboidratos recaem sobre a fração solúvel, podendo levar a estimativas viesadas da referida fração. Na tabela de alimentos do software CNCPS v. 6.1 os valores de açúcar solúvel do farelo de soja variam de 81 a115 $\mathrm{g} \mathrm{kg}^{-1}$, estes valores estão mais próximos dos encontrados no presente trabalho.
Como esperado houve diferença estatística na concentração de carboidratos solúveis dos alimentos estudados $(\alpha<0,05)$. No caso das duas técnicas usadas para determinação dos $\mathrm{CHO}$ solúveis não houve diferença significativa ( $\alpha>0,05)$, porém houve efeito da interação entre técnica e alimento (Tabela 2). Devido ao efeito positivo da interação foi realizada uma nova análise de variância para cada alimento com o intuito de determinar em qual deles haveria diferença significativa entre as duas técnicas.

Tabela 2. Análise de Variância para os valores médios das técnicas analisadas, os alimentos e a interação entre técnica e alimento.

\begin{tabular}{lccccc}
\hline \multicolumn{1}{c}{$\mathbf{F V}^{\mathbf{1}}$} & $\mathbf{G L}^{\mathbf{2}}$ & $\mathbf{S Q}^{\mathbf{3}}$ & $\mathbf{Q M}^{\mathbf{4}}$ & $\mathbf{F}_{\mathbf{0}}$ & $\mathbf{P}$ \\
\hline Técnica & 1 & 28 & 28.06024 & 0.427474 & 0.51457 \\
Alimento & 3 & 834495 & 278165.1 & 4237.606 & 0.00000 \\
Interação & 3 & 1667 & 555.6991 & 8.465599 & 0.00004 \\
Resíduo & 112 & 7352 & 65.64203 & - & - \\
TOTAL & 119 & 843542 & - & - & - \\
\hline
\end{tabular}

${ }^{1}$ Fator/variável analisada ${ }^{2}$ Grau de Liberdade ${ }^{3}$ Soma de Quadrados ${ }^{4}$ Quadrado Médio

Fonte: Elaboração dos autores.

Ao submeter os resultados à nova análise de variância, todos os alimentos testados, com exceção do farelo de soja, apresentaram valores de carboidratos solúveis diferente de acordo com a técnica utilizada. O milho e o capim tiveram valores menores quando a técnica utilizada foi a antrona e o oposto foi observado para a cana de açúcar.

As altas concentrações de carboidratos solúveis da cana causavam instabilidade na leitura do espectrofotômetro a partir da absorbância 0,9. Provavelmente, a grande massa de carboidrato solúvel da amostra de cana ultrapassava a capacidade do equipamento. Segundo a Lei de Lambert-Beer (BRACHT; KELMER-BRACH; AMADO, 2003), deve existir uma relação linear entre a concentração da amostra e a absorbância. Contudo, essa linearidade é válida dentro de certos limites, a partir de determinada concentração deixa de haver proporcionalidade entre concentração e absorbância. A faixa de linearidade depende da substância e das interações entre as substâncias, mas depende também do aparelho. Geralmente, se observa problemas na linearidade a partir de absorbâncias entre 1,5 e 2 (BRACHT; KELMERBRACH; AMADO, 2003). Porém, quando se utiliza aparelhos com baixa precisão recomenda-se usar concentrações de amostras que produzam valores de absorbância entre 0,2 e 0,9 para evitar extrapolar os limites do espectrofotômetro (GUTIERREZ, 2011). No presente trabalho o único alimento que não apresentou diferença estatística nos carboidratos solúveis determinado pelas duas técnicas testadas foi o farelo de soja. Justamente o alimento que possuía teores intermediários de açúcar solúvel. Todos os outros possuíam ou valores muito baixos (capim estrela e grão de milho) ou muito altos (cana de açúcar) de carboidratos solúveis. Essas evidências nos levam a crer que talvez as diferenças observadas sejam consequência da sensibilidade e capacidade do equipamento de espectrofotometria 
utilizado e não das diferentes técnicas. Portanto, propõe-se mais pesquisas sobre o assunto para tentar adequar os procedimentos analíticos de forma a permitir determinações mais acuradas mesmo com espectrofotômetros de baixa precisão. A proposta mais imediata seria realizar diluições das amostras com maior conteúdo de açúcar e aumentar a massa de amostra com baixa concentração com o objetivo de ajustar a quantidade de açúcar a ser determinado para que os valores de absorbância se situem entre 0,2 e 0,9 .

\section{Conclusão}

As técnicas do fenol e da antrona se equivaleram para determinar os açúcares solúveis do farelo de soja. O mesmo não foi observado para o grão de milho, capim estrela e cana de açúcar, provavelmente, porque esses alimentos tinham concentrações de açúcares que extrapolavam os limites máximo e mínimo de detecção do equipamento usado. Portanto, recomenda-se mais pesquisa sobre a melhor diluição da amostra para determinação de açúcar solúvel pelos métodos estudados.

\section{Referências}

BERTIPAGLIA, L. M. A.; MELO, G. M. P. de; SUGOHARA, A.; MELO, W. J.; BERTIPAGLIA, L. A. Alterações bromatológicas em soja e milho processados por extrusão. Revista Brasileira de Zootecnia, Viçosa, MG, v. 37, n. 11, p. 2003-2010, 2008.

BRACHT, A.; KELMER-BRACHT, A. M.; AMADO, C. A. B. Espectrofotometria e fluorometria. In: BRACHT, A.; ISHII-IWAMOTO, E. L. (Org.). Métodos de laboratório em bioquímica. Barueri: Manole, 2003. p. 77-192.

CANIATO, F. F.; GUIMARÃES, C. T.; SCHAFFERT, R. E.; ALVES, V. M. C.; KOCHIAN, L. V.; BOREM, A.; KLEIN, P. E.; MAGALHÃES, J. V. Genetic diversity for aluminum tolerance in sorghum. Theoretical and Applied Genetics, Berlin, v. 114, n. 5, p. 836-876, 2007.

CREECH, R. G. Carbohydrate synthesis in maize. Advances in Agronomy, San Diego, v. 20, p. 275-289, 1968.
CNCPS - CORNEL UNIVERSITY - DEPARTAMENT OF ANIMAL SCIENCE. CNCPS, v. 6. 1, 2008.

DERIAZ, R. E. Routine analysis of carbohydrate and lignin in herbage. Journal of Science and Food Agriculture, UK, v. 12, n. 2, p. 150-160, 1961.

DIAS, M.; LEÃO, M. I.; DETMANN, E.; VALADARES FILHO, S. de C.; VASCONCELOS, A. M.; SOUZA, S. M. de; PAULINO, M. F.; MURÇA, T. B. Técnicas para estimativa de digestibilidade e produção microbiana em bovinos. Revista Brasileira de Zootecnia, Viçosa, MG, v. 37, n. 3, p. 504-512, 2008.

DUBOIS, M.; GILlES, K. A.; HAMILTON, J. K.; REBERS, P. A.; SMITH, F. Colorimetric method for determination of sugars and related substances. Analitycal Biochemistry, Orlando, v. 28, n. 3, p. 350-356, 1956.

FAVORETO, M. G.; DERESZ, F.; FERNANDES, A. M.; VIEIRA, R. A. M.; FONTES, C. de A. A. Avaliação nutricional na grama-estrela cv. Africana para vacas leiteiras em condições de pastejo. Revista Brasileira de Zootecnia, Viçosa, MG, v. 37, n. 2, p. 319-327, 2008.

FERNANDES, A. M.; QUEIROZ, A. C. de; PEREIRA, J. C.; LANA, R. de P.; BARBOSA, M. H. P.; FONSECA, D. M.; DETMANN, E.; CABRAL, L. S.; PEREIRA, E. S.; VITTORI, A. Composição químico-bromatológica de variedades de cana-de- açúcar (SaccharumsppL.) com diferentes ciclos de produção (precoce e intermediário) em três idades de corte. Revista Brasileira de Zootecnia, Viçosa, MG, v. 31, n. 4, p. 977-985, 2003 a.

. Fracionamento e cinética da degradação in vitro dos carboidratos constituintes da cana-de-açúcar com diferentes ciclos de produção em três idades de corte. Revista Brasileira de Zootecnia, Viçosa, MG, v. 32, n. 6, p. 1778-1785, 2003b. Suplemento 1.

GUTIERREZ, A. C. Comunicação pessoal. Dois Vizinhos: Universidade Tecnológica Federal do Paraná, 2011.

HASHIMOTO, J. H.; ALCALDE, C. R.; ZAMBOM, M. A.; SILVA, K. T.; MACEDO, F. de A. F.; LIMA, E. S.; SILVA, J. F. C.; VÁSQUEZ, H. M.; ARAÚJO, S. A. C.; ROCHA, T. C.; COSTA, D. P. B. Fracionamento de carboidratos e compostos nitrogenados de genótipos de capim-elefante aos 56 dias de rebrota. Revista Brasileira de Zootecnia, Viçosa, MG, v. 37, n. 11, p. 1928-1933, 2007.

MALAFAIA, P. A. M.; VALADARES FILHO, S. de C.; VIEIRA, R. A. M.; SILVA, J. F. C.; PEREIRA, J. C. Determinação das frações que constituem os carboidratos totais e da cinética ruminal da fibra em detergente neutro de alguns alimentos para ruminantes. Revista Brasileira de Zootecnia, Viçosa, MG, v. 27, n. 4, p. 790-796, 1998. 
MERTENS, D. R. Using fiber and carbohydrate analyses to formulate dairy rations. Journal of Animal Science, Wisconsin, v. 80, n. 7, p. 1463-1481, 1996.

PEREIRA, E. S.; QUEIROZ, A. C. de; PAULINO, M. F.; CECON, P. R.; VALADARES FILHO, S. de C.; MIRANDA, L. F.; FERNANDES, A. M.; CABRAL, L. da. S. Determinação das frações proteicas e de carboidratos e taxas de degradação in vitro da cana-deaçúcar, da cama de frango e do farelo de algodão. Revista Brasileira de Zootecnia, Viçosa, MG, v. 29, n. 6, p. 18871893, 2000.

SILVA, D. J. da; QUEIROZ, A. C. de. Análise de alimentos: métodos químicos e biológicos. 3. ed. Viçosa: UFV, 2004. $235 \mathrm{p}$.

SILVA, E. J. A. da; BORGATTI, L. M. O.; MEYER, P. M.; MARINO, C. T.; RODRIGUES, P. H.. M. Efeitos do teor de carboidratos solúveis sobre as características da silagem de cana-de-açúcar. Revista Brasileira de Zootecnia, Viçosa, MG, v. 37, n. 8, p. 1375-1382, 2008.
SNIFFEN, C. J.; O'CONNOR, J. D.; VAN SOEST, P. J.; FOX, D. G.; RUSSELL, J. B. A net carbohydrate and protein system for evaluating cattle diets. II. Carbohydrate and protein availability. Journal of Animal Science, Champaign Illinois, v. 70, n. 7, p. 3562-3577, 1992.

VAN SOEST, P. J. Nutritional ecology of the ruminant. 2. ed. Ithaca: Cornell University Press, 1994. 476 p.

Development of a comprehensive system of feed analyses and its aplication to forages. Journal of Animal Science, Champaign Illinois, v. 2, n. 1, p. 119-128, 1967.

VIANNA, J. F.; PIRES, D. X.; VIANA, L. H. Processo químico industrial de extração de óleo vegetal: um experimento de química geral. Química Nova, São Paulo, v. 22, n. 5 , p. $765-768,1999$.

VIEIRA, R. A. M.; PEREIRA, J. C.; MALAFAIA, P. A. M.; QUEIROZ, A. C. de; GONÇALVES, A. L. Fracionamento dos carboidratos e cinética de degradação in vitro da fibra em detergente neutro da extrusa de bovinos a pasto. Revista Brasileira de Zootecnia, Viçosa, MG, v. 29, n. 3, p. 889-897, 2000a. 